\title{
Brachydactyly-elbow wrist dysplasia syndrome
}

INSERM

\section{Source}

INSERM. (1999). Orphanet: an online rare disease and orphan drug data base.

Brachydactyly-elbow wrist dysplasia syndrome. ORPHA:1275

Brachydactyly-elbow wrist dysplasia syndrome is a rare, genetic bone development disorder characterized by dysplasia of all the bony components of the elbow joint, abnormally shaped carpal bones, wrist joint radial deviation and brachydactyly. Patients typically present with slight flexion at the elbow joints (with impossibilty to perform active extension) and usually associate a limited range of motion of the elbow, wrist and finger articulations. Camptodactyly and syndactyly have also been reported. 